\title{
Práticas das enfermeiras e políticas de saúde pública em Campinas, São Paulo, Brasil
}

\author{
Nursing practice and public health policy \\ in Campinas, São Paulo, Brazil
}

Eliete Maria Silva 1

Márcia Regina Nozawa 1

José Carlos Silva 2

Silvia A. M. L. D. Carmona 2

1 Departamento de Enfermagem, Faculdade de Ciências Médicas, Universidade Estadual de Campinas. Cidade Universitária Zeferino Vaz, C. P. 6111, Campinas, SP 13083-970, Brasil. emsilva@unicamp.br nozawa@unicamp.br 2 Coordenadoria Setorial de Recursos Humanos, Secretaria Municipal de Saúde de Campinas. Av. Anchieta 200, 11 o andar Campinas, $S P$

13015-100, Brasil.

\begin{abstract}
Redemocratization in the 1970s brought about changes in the public health system in Brazil. The Unified National Health System (SUS) was implemented in 1988, based on local and regional administrative systems. This was an important step that resulted in greater local control and the introduction of new technologies. This study focuses on the local health system in Campinas, a relatively affluent and technologically advanced region some $100 \mathrm{~km}$ from the city of São Paulo in Southeast Brazil. Qualitative and quantitative methods were used to evaluate the work of 233 nurses in the local health system. The first nurse was hired in 1977, and now there are 53 nurses working in specific areas: 10 in the central health administration, 36 in district administrations, and the rest in local services. Nursing services are organized in six main areas: administration, coordination of human resources, education, information technology, health surveillance, and health administration. Nursing intervention may be found in various areas, but it generally focuses on medical consultations, and there is little emphasis on collective activities and health promotion. Local health objectives can only be achieved by creating new practices that promote collective health.
\end{abstract}

Key words Health Policy; Nursing Staff; Public Health Practice

Resumo Desde a década de 70 o sistema de saúde vem se transformando com a redemocratização do Estado Brasileiro. O SUS representou um importante passo para o fortalecimento dos sistemas de administração locais e regionais. Tal situação tem contribuído para o aumento do controle local e para as mudanças no processo de trabalho. Este estudo considera essas mudanças no sistema local de saúde em Campinas, São Paulo, e analisa, quantitativa e qualitativamente, as práticas de 233 enfermeiras da rede municipal em relação às políticas de saúde locais. Cerca de $58 \%$ trabalham em serviços locais e $42 \%$ em serviços especializados, em níveis distritais e central de administração. Os serviços de enfermagem organizam-se em seis áreas principais: administração, coordenação de recursos humanos, educação de pessoal, informática, administração em saúde e vigilância em saúde. A intervenção das enfermeiras tem se dirigido às diversas áreas, mas continua centrada nas consultas médicas, com pequena ênfase em atividades coletivas e de promoção à saúde. Concluímos que novas práticas de promoção à saúde coletiva precisam ser fomentadas de acordo com os objetivos de desenvolvimento da saúde em âmbito local.

Palavras-chave Política de Saúde; Recursos Humanos de Enfermagem; Prática de Saúde Pública 


\section{A problemática investigada}

A partir do final da década de 1970, o Brasil vem vivenciando um processo de redemocratização do Estado e da sociedade como um todo. Esse processo foi desencadeado, por um lado, pela crise do Estado, convergente com uma profunda crise econômica que coincide com a ruptura de padrões de crescimento sustentados na articulação do Governo com empresas multinacionais e nacionais privadas. Tal crise orgânica expressou-se também por crises financeiras e fiscais, num quadro de extremas desigualdades, que afetaram-lhe a legitimidade necessária para arbitrar conflitos redistributivos (Mendes, 1994). Por outro lado, situam-se os movimentos operários e de participação popular, dentre os quais se destacam aqueles ligados ao setor saúde. As associações de moradores de bairros, como parte do movimento urbano organizado, tiveram significativa contribuição na expressão das demandas por extensão da cobertura dos serviços de saúde (Smek, 1986).

Nesse mesmo período, outro aspecto relevante no âmbito interno do setor saúde era a dinâmica dos serviços prestados pelas três esferas de governo (nacional, estadual e municipal) que operavam de forma parcelar e não integrada. Tal situação revelava-se onerosa e pouco eficiente em termos de impactos positivos na saúde da população e, ao mesmo tempo, refletia um processo global de mercantilização da saúde e de privatização da atenção às doenças.

Em linhas gerais, ocorre também, no último quarto do século $\mathrm{XX}$, o reconhecimento de que é restrito o campo de atuação das atividades médicas, mesmo quando são predominantemente preventivas, uma vez que é pequeno o impacto das mesmas sobre os determinantes da morbi-mortalidade da população. A compreensão de que as condições de saúde dos grupos populacionais guardam estreita relação com as condições de vida em geral, mais do que com a atenção às doenças em particular, estimulou a estruturação de programas prioritários a grupos de riscos, a busca de atendimentos integrais, contínuos e de boa qualidade, com avaliação de resultados, evitando-se a medicalização excessiva e ineficaz.

Articulados a essas questões e de modo coerente com as propostas de Atenção Primária à Saúde (APS) da Organização Mundial de Saúde (OMS), vários técnicos, organizações da sociedade civil, entidades profissionais e alguns governos municipais iniciaram o árduo caminho da extensão de cobertura dos servi- ços de saúde à população rural (que diminuiu drasticamente no país a partir dos anos 70) e principalmente àquela periférica das médias $\mathrm{e}$ grandes cidades.

A municipalização da saúde, estratégia fundamental para viabilizar o processo de descentralização do setor saúde no país, acarreta e pressupõe o aumento do poder de operação e decisões em âmbito local, trazendo à cena política inúmeros atores sociais, representantes de distintos interesses, visões de mundo e práticas dentre as quais operam as estratégias de clientelismo e corporativismos (Mendes, 1994).

Deste modo, transformações nos serviços e mudanças efetivas nas ações de saúde realizadas pelos municípios, demandavam e continuam dependendo de princípios ético-políticos mais comprometidos com a democracia e com a concepção de saúde como direito de cidadania, enquanto projeto contraposto ao modelo neoliberal, ainda hegemônico no setor de saúde brasileiro.

As transformações nas políticas públicas têm relação com a incorporação de tecnologias no desenvolvimento do trabalho assistencial e na organização e gerência dos serviços de saúde, bem como na ampliação e diversificação dos agentes que trabalham nos serviços de saúde municipais.

Objetivamos estudar as relações do processo de descentralização em saúde no último quarto do século XX, com as práticas de atenção à saúde pública no âmbito da Secretaria Municipal de Saúde (SMS) de Campinas, São Paulo, Brasil, destacando particularmente o trabalho das enfermeiras.

A opção pelo coletivo enfermeiras (no feminino) não desconsidera a participação de profissionais homens, mas pretende acentuar as características de gênero presentes na profissão, numa clara subversão à norma gramatical.

Entendemos trabalho como prática social, ato social, que se completa e se articula aos demais trabalhos em saúde, sempre em resposta às necessidades sociais, o que permite enxergar a profunda ligação com a economia, história, cultura e a política e compreender os constrangimentos estruturais a que está sujeito. Mesmo que alguém possa agir isoladamente, o trabalho não é ato individual, sempre faz parte de coletivos (nos quais as ações se encaixam, se conectam e se completam) que regulam sua liberdade interna de criação (Schraiber, 1996).

A produção científica da enfermagem brasileira, na perspectiva de enfermagem como trabalho, é considerável e teve início na década de 80 com alguns estudos que têm sido referência clássica nessa discussão, entre eles, 
destacamos os realizados por Almeida \& Rocha (1986), Silva (1986), Melo (1986) e Rezende (1986).

\section{O percurso da investigação}

Este estudo teve por campo a SMS do Município de Campinas, São Paulo, que se situa a $100 \mathrm{~km}$ da Cidade de São Paulo e conta com uma população aproximada de 958 mil habitantes. Segundo a divisão político-administrativa da Secretaria de Estado da Saúde (SES), integra, junto com outros 38 municípios, a XII Região que totaliza dois milhões de habitantes.

No âmbito municipal, o Sistema Único de Saúde (SUS) é constituído por: 44 Unidades Básicas de Saúde (Centros de Saúde); 13 Centros de Referência; três Ambulatórios de Especialidades; dois Hospitais Universitários; um Hospital Municipal; 13 Hospitais Privados (Lucrativos e Filantrópicos); uma Maternidade Privada Conveniada; três Unidades de Pronto Atendimento e um Serviço de Atendimento Pré-Hospitalar - Serviço de Atendimento Médico de Urgência (SAMU).

Excetuando-se os hospitais universitários, os privados/filantrópicos e a maternidade, todos os demais serviços são parte integrante da estrutura administrativa da SMS. Desde maio de 1996, o município está habilitado na modalidade de gestão plena da atenção básica e, em 1998, em decorrência da NOB/96 (MS, 1996), passou à gestão plena do sistema municipal de saúde.

Para este estudo, priorizamos a chamada rede básica de serviços, que inclui prioritariamente os três primeiros grupos de unidades, ou seja, os centros de saúde, os centros de referência e os ambulatórios especializados. Também incluímos a estrutura distrital de organização dessa rede de atendimento à saúde pública no município, bem como dois setores de nível central o Departamento de Saúde (DS) da SMS e a Coordenadoria Setorial de Relações do Trabalho (CSRT).

A coleta de dados envolveu pesquisa a documentos, informações sobre recursos humanos disponibilizados pelos respectivos setores da SMS e consulta a questionários aplicados a enfermeiras da rede municipal em oficinas de diagnóstico das práticas de enfermagem, parte das atividades do Projeto de Qualificação das Práticas de Enfermagem, ocorridas em meados de 1998. Investigamos e analisamos todos os documentos produzidos pelos diversos setores da SMS e disponíveis no Centro de Documentação (Cedoc) e Centro de Educação dos Traba- lhadores da Saúde (CETS), conforme relação descrita na Tabela 1.

No ano de 1998, por iniciativa do DS, da CSRT e do CETS da SMS de Campinas, com parceria do Departamento de Enfermagem da Faculdade de Ciências Médicas da Universidade Estadual de Campinas (UNICAMP), teve início o Projeto de Qualificação das Práticas de Enfermagem da Rede Municipal de Saúde.

Entre outros objetivos, tal projeto contemplava diagnosticar a prática de enfermagem para subsidiar o processo de qualificação da mesma. Uma das etapas desse diagnóstico foi realizada através do desenvolvimento de oito oficinas de trabalho nos meses de maio a julho de 1998, as quais contaram com a participação de nove enfermeiras da UNICAMP e da Pontifícia Universidade Católica de Campinas (PUCC) e 162 enfermeiras, ou seja, $69,5 \%$ da totalidade lotadas na rede básica de serviços da SMS. Na fase inicial de todas as oficinas de trabalho aplicou-se um questionário individual que solicitava a cada profissional a descrição de suas atividades cotidianas de trabalho. As respostas a essa questão correspondem aos dados qualitativos que foram também objeto de análise.

Assim, o desenvolvimento deste estudo compreendeu a sistematização das fontes documentais e identificação de aspectos relevantes em consideração aos seus objetivos; a pesquisa e agregação dos dados quantitativos; análise de dados qualitativos e a identificação das convergências entre as fontes documentais e os dados quantitativos e qualitativos.

\section{O sistema de saúde municipal}

No final da década de 70, as prefeituras de alguns municípios brasileiros, dentre as quais destacamos: Campinas, Londrina, Niterói, Montes Claros, tiveram governos comprometidos com a defesa dos interesses da maioria da população e estruturaram, com recursos próprios, serviços de saúde apoiados em quatro características básicas: a democratização da atenção médica; a extensão de cobertura com a instalação de redes básicas de atenção à saúde, que previam a hierarquização dos níveis de atenção; a atenção integral e a participação comunitária (Carvalho, 1993; Pimenta, 1993).

Com ações dirigidas às pessoas, ao meio e à constituição de informações estatísticas, demográficas e de produção de serviços, estruturou-se uma rede de postos comunitários de saúde na periferia dessas cidades e suas respectivas áreas rurais. O programa prioritariamente desenvolvido era o Materno-Infantil, 
Tabela 1

Documentos produzidos pelos diversos setores da Secretaria Municipal de Saúde de Campinas e disponíveis no Centro de Documentação e Centro de Educação dos Trabalhadores da Saúde.

\begin{tabular}{|c|c|c|}
\hline Documentos & Data & Procedência \\
\hline Relatório Anual da Secretaria Municipal de Saúde & 1978 & Prefeitura Municipal de Campinas \\
\hline Encontros de Saúde - Conclusões & 1978 & Prefeitura Municipal de Campinas \\
\hline Relatório Anual da Secretaria Municipal de Saúde & 1979 & Prefeitura Municipal de Campinas \\
\hline I Seminário de Auxiliares de Saúde & 1984 & Secretaria de Saúde/Prefeitura Municipal de Campinas \\
\hline Il Seminário de Auxiliares de Saúde & 1987 & Secretaria de Saúde/Prefeitura Municipal de Campinas \\
\hline I Conferência Municipal de Saúde & 1990 & Secretaria de Saúde/Prefeitura Municipal de Campinas \\
\hline Il Conferência Municipal de Saúde & 1991 & Secretaria de Saúde/Prefeitura Municipal de Campinas \\
\hline III Conferência Municipal de Saúde & 1994 & Secretaria de Saúde/Prefeitura Municipal de Campinas \\
\hline Sumário de dados - Saúde/Município de Campinas & 1995 & $\begin{array}{l}\text { Secretaria de Planejamento e Meio Ambiente/ } \\
\text { Secretaria de Saúde/Prefeitura Municipal de Campinas }\end{array}$ \\
\hline $\begin{array}{l}\text { Atribuições do enfermeiro na rede de serviços } \\
\text { de saúde do SUS - Campinas }\end{array}$ & 1996 & Secretaria de Saúde/Prefeitura Municipal de Campinas \\
\hline 4ạ Conferência Municipal de Saúde - Relatório Final & 1997 & $\begin{array}{l}\text { Sistema Único de Saúde/Secretaria de Saúde/ } \\
\text { Prefeitura Municipal de Campinas }\end{array}$ \\
\hline $\begin{array}{l}\text { Relatório Final do III Simpósio Internacional de Atenção } \\
\text { Pré-hospitalar às Urgências e Traumas e Seminário } \\
\text { de Organização de Sistemas de Urgência. }\end{array}$ & 1997 & $\begin{array}{l}\text { Sistema Único de Saúde/Secretaria de Saúde/ } \\
\text { Prefeitura Municipal de Campinas }\end{array}$ \\
\hline $\begin{array}{l}\text { História da enfermagem na rede básica de Campinas } \\
\text { e Projeto de Qualificação das Práticas de Enfermagem } \\
\text { de } 1988 \text { a } 1999\end{array}$ & 1999 & $\begin{array}{l}\text { Grupo de Coordenação do Projeto de Qualificação } \\
\text { das Práticas de Enfermagem/Secretaria de Saúde/ } \\
\text { Prefeitura Municipal de Campinas }\end{array}$ \\
\hline
\end{tabular}

mas outros atendimentos a crônicos e grupos de riscos foram sendo implantados, tais como os de Saúde Mental, Saúde Bucal, Vacinação e de Controle de Hipertensão Arterial.

A avaliação do trabalho dos Postos Comunitários ocorria, freqüentemente, com participação de representantes das organizações comunitárias. A equipe de saúde trabalhava com indicadores de cobertura, de rendimento e de concentração das ações desenvolvidas. Os trabalhadores que majoritariamente atuavam nesses Postos eram os médicos e os auxiliares de saúde. Estes últimos eram recrutados na comunidade atendida pela unidade sanitária, sem a exigência de formação específica em saúde e recebiam treinamento em serviço.

No ano de 1978, Campinas, que já contava com uma rede instalada de vinte postos de saúde, em parceria com Londrina e Niterói, foi sede do Encontro Municipal de Saúde da Região Sudeste, congregando 61 municípios de todas as regiões do país. Neste encontro foram tecidas várias críticas ao modelo de saúde vigente no Brasil, com gastos escusos e excesso de internações hospitalares desnecessárias.
Para viabilizar a Atenção Primária reivindicouse, dentre outros aspectos, a revisão da política tributária de modo a garantir um maior aporte de recursos aos municípios. Tal revisão vem sendo lentamente operada no país, sendo objeto de controvérsia na atual crise financeira, da necessidade do ajuste fiscal brasileiro e da disputa entre os níveis de governo. Em relação à saúde, algumas garantias de aplicação e repasse financeiro foram legisladas somente no início dos anos 1990 e continuam carecendo de efetiva implantação e transparência.

A partir da Lei 6.229/75 do Sistema Nacional de Saúde (Brasil, 1975), que definiu como competência dos municípios a manutenção de serviços de saúde de interesse das populações locais e a vigilância epidemiológica, o Município de Campinas passou a integrar os seus serviços de promoção e recuperação da saúde com aqueles prestados pelos níveis estadual e federal. Em junho de 1978, as Secretarias de Saúde do Estado de São Paulo e da Prefeitura Municipal firmaram convênio que possibilitou ao município funcionar como área piloto para a regionalização em saúde. A programação con- 
junta de atividades foi coordenada por uma comissão inter-institucional e ocorreu de forma progressiva através do desenvolvimento ou da implantação de ações comuns, da uniformização dos registros, coletas e processamentos de dados, da previsão conjunta de recursos, realização de treinamentos, definição de áreas de cobertura das unidades antigas e novas da Prefeitura e do Estado, bem como, pela definição de critérios de referência e contra-referência, e com o Instituto Adolfo Lutz, para o apoio laboratorial.

Na primeira metade da década de 80 , as políticas públicas de saúde buscaram responder de modo mais efetivo ao ideário da articulação entre os três níveis de governo, presente no movimento pela Reforma Sanitária, através das Ações Integradas de Saúde (AIS). Novamente, Campinas integrou com Itu, São Roque, Botucatu e Ribeirão Preto, o grupo pioneiro de municípios do Estado de São Paulo a assinar esse convênio nos anos de 1983 e 1984 (Almeida et al., 1997; Tanaka et al., 1991). Nessa ocasião, o Município de Campinas contava com 31 centros de saúde. Realizava concursos públicos de ingresso, sendo que antes as seleções eram predominantemente clientelistas. A estrutura administrativa da SMS iniciava sua organização de modo descentralizado em três grandes regiões.

A partir de 1986, com a aprovação da Lei do Exercício Profissional da Enfermagem (Brasil, 1986), os serviços de saúde no país passaram a ter dez anos para realizar formação de todo o pessoal de nível elementar que exercesse atividades em enfermagem. Para formar este quadro de pessoal, a SMS optou por desenvolver um programa de educação em serviço, denominado Projeto Larga Escala (PLE), que pressupunha um grande envolvimento das enfermeiras no ensino e supervisão dos auxiliares de saúde em formação, para os habilitar como auxiliares de enfermagem.

O PLE teve importante impacto na qualificação da força de trabalho em enfermagem na rede básica de serviços de saúde de Campinas, e também daqueles profissionais que atuavam no Hospital Mário Gatti, que é uma autarquia municipal. A Figura 1 apresenta a composição de recursos humanos em enfermagem no período compreendido entre 1986 e 1998. Destaca-se, entre os anos de 1992 a 1996, o impacto do referido projeto na formação de auxiliares de enfermagem.

No final dos anos 80 e início dos 90, várias atividades exercidas somente pelos Centros de Saúde (CS) da rede estadual passaram a ser incorporadas às unidades municipais, tais como: a vigilância epidemiológica e programa de vacinação, incluindo o esquema de vacinação antirábica. Naquele momento, as 38 unidades prestavam atendimento nas áreas programáticas da criança, adulto e mulher, realizavam visitas domiciliares e grupos educativos. Tanto a infraestrutura foi melhorada, havendo reformas em vinte unidades, quanto os recursos humanos foram priorizados. Estruturaram-se os níveis de supervisão por regiões e iniciou-se a organização da gerência local no âmbito de cada CS.

As enfermeiras em Campinas foram agentes estratégicos, quer seja na qualificação do pessoal de nível elementar e médio na rede de atenção à saúde, quer seja na gerência dos serviços locais e distritais.

\section{As enfermeiras no serviço de saúde pública municipal}

O período de maior contratação de enfermeiras no Município de Campinas ocorreu a partir do Sistema Unificado e Descentralizado de Saúde (SUDS), estruturado no final da década de 1980, a exemplo do que ocorreu em vários outros municípios brasileiros. A análise do processo de municipalização da saúde em diversas cidades do estado de São Paulo, conduzida por Tanaka et al. (1991) evidenciou que, sob a influência das AIS e posteriormente do SUDS, um substancial crescimento na absorção de algumas categorias profissionais de nível universitário no setor público, especialmente dos médicos, cirurgiões dentistas e enfermeiras, em ordem crescente de importância. Segundo os mesmos autores, as enfermeiras integram a categoria profissional universitária que apresentou maior expansão nos estabelecimentos públicos sem internação do estado de São Paulo, tanto que para os anos de 1985 e 1987 teve um incremento da ordem de $57 \%$.

Estudo relativo ao mesmo período e referente ao processo de municipalização, realizado por Pereira et al. (1997) em Ribeirão Preto, município com cerca de 500 mil habitantes localizado no nordeste do Estado de São Paulo, indica que a inserção de enfermeiras na rede de saúde municipal, que teve início em 1983, apresentou um crescimento de $17.200 \%$ em relação ao ano de 1997.

Tal taxa justificou-se pela capacidade desses profissionais atuarem na organização e implementação do funcionamento da rede básica municipal de saúde, uma vez que entre os anos 80 e 90 ocorreu significativa ampliação física da rede municipal. Ribeirão Preto passou de 13 postos de atendimento médico (em 1983), para 
Figura 1

Distribuição de auxiliares de saúde, auxiliares de enfermagem e auxiliares de enfermagem formados pelo Projeto

Larga Escala. Secretaria Municipal de Saúde de Campinas, São Paulo, 1998.

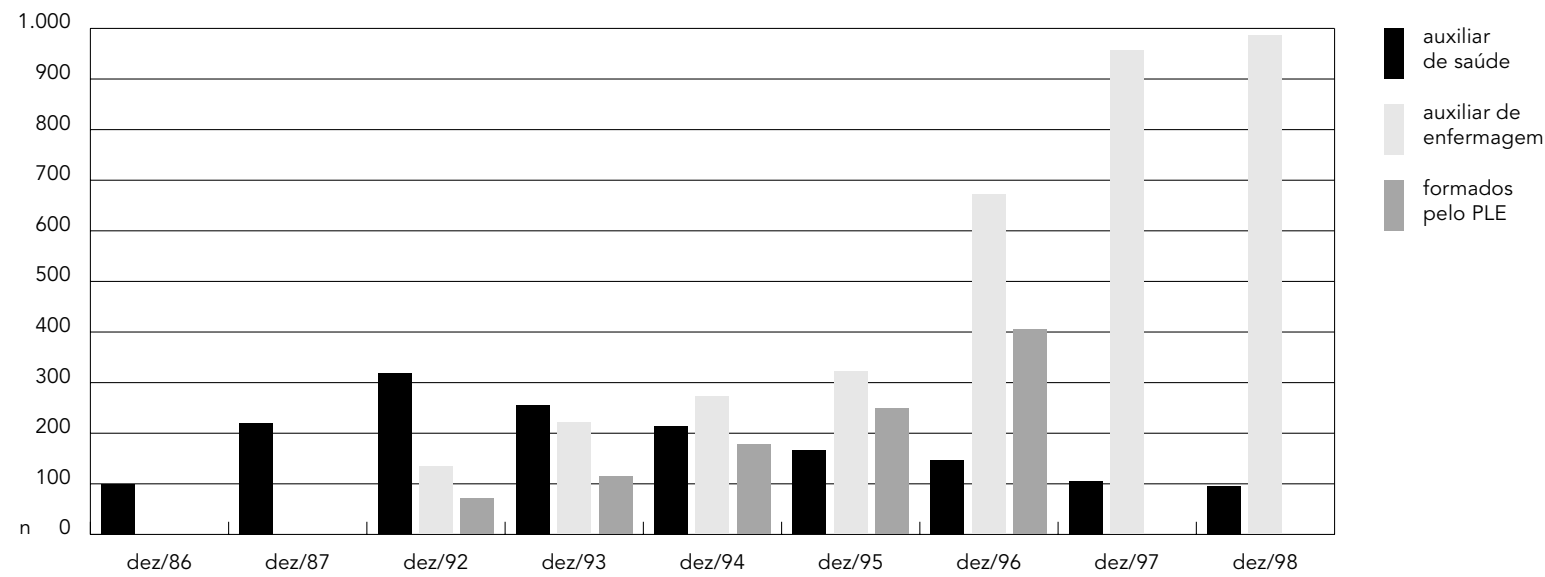

cinco unidades básicas e distritais de saúde, 26 unidades básicas de saúde, dois núcleos de atenção psicossocial, um ambulatório de especialidades e um regional de saúde mental (em 1996). O crescimento físico da rede foi acompanhado pela implantação de atividades antes não realizadas plenamente por todas as unidades, tais como: vacinação, registros em prontuários individuais de pacientes e sistemas de informações epidemiológicas e gerenciais em âmbito local, as quais demandaram a contratação de um número significativo de enfermeiras, de pessoal auxiliar de enfermagem, bem como de outros profissionais.

Contudo, apesar do crescimento da inserção de enfermeiras em Campinas, guardar algumas semelhanças com os achados de Ribeirão Preto, destacam-se as diferenças. O município campineiro inicia a inserção de enfermeiras em 1977, contratando três profissionais que, a partir de julho de 1978, integraram um grupo de sete atuando em âmbito local. Nesse primeiro momento, as contratadas ficavam diretamente responsáveis por cerca de três Postos Comunitários. A relação ideal, preconizada à época, era a de um enfermeiro para cada dois postos, de modo a garantir maior contato com a comunidade e participação na atenção direta às pessoas e aos grupos, realizando diagnósticos e tratamentos das patologias mais freqüentes, conforme normalização da SMS e definição de critérios de riscos, não somente biológico, mas também social, econômico ou cultural.
Vale mencionar, para justificar a relevância social desta abordagem mais ampla do risco, que metade da população brasileira participava nos anos 80 com menos de $14 \%$ da renda nacional, medida pelo Produto Interno Bruto (PIB), sendo que $70 \%$ das pessoas empregadas ganhavam menos de dois salários mínimos. Tal concentração de renda tende a ser agravada na atual crise financeira, com o aumento significativo do desemprego e do emprego informal.

Contudo, a prioridade para a atenção comunitária (característica da constituição da rede campineira de serviços de saúde) sofreu um relativo abandono com a incorporação mais abrangente da assistência médica nas unidades de saúde, a partir da implantação das AIS. Várias dificuldades foram reconhecidas e, na parceria entre médicos e auxiliares de saúde, a estratégia de "delegação de atividades" nem sempre aconteceu de modo tranqüilo e solidário.

As auxiliares de saúde passaram a se organizar reivindicando melhores condições de trabalho, salários e carreira. Assinalavam em seus encontros, ocorridos entre os anos de 1984 e 1987, que as tarefas administrativas solicitadas pela SMS tinham caráter burocrático, atendendo mais aos interesses formais de prestação de contas, do que para o planejamento e efetivação do trabalho. Tal realidade sofreu mudanças lentas e freqüentemente descontínuas.

Conforme apresentamos na Figura 2, as enfermeiras apresentaram uma inserção crescente no quadro de pessoal da SMS a partir de 
Distribuição de enfermeiras na rede básica de serviços de saúde de acordo com o ano de admissão.

Secretaria Municipal de Saúde de Campinas, São Paulo, 1998.

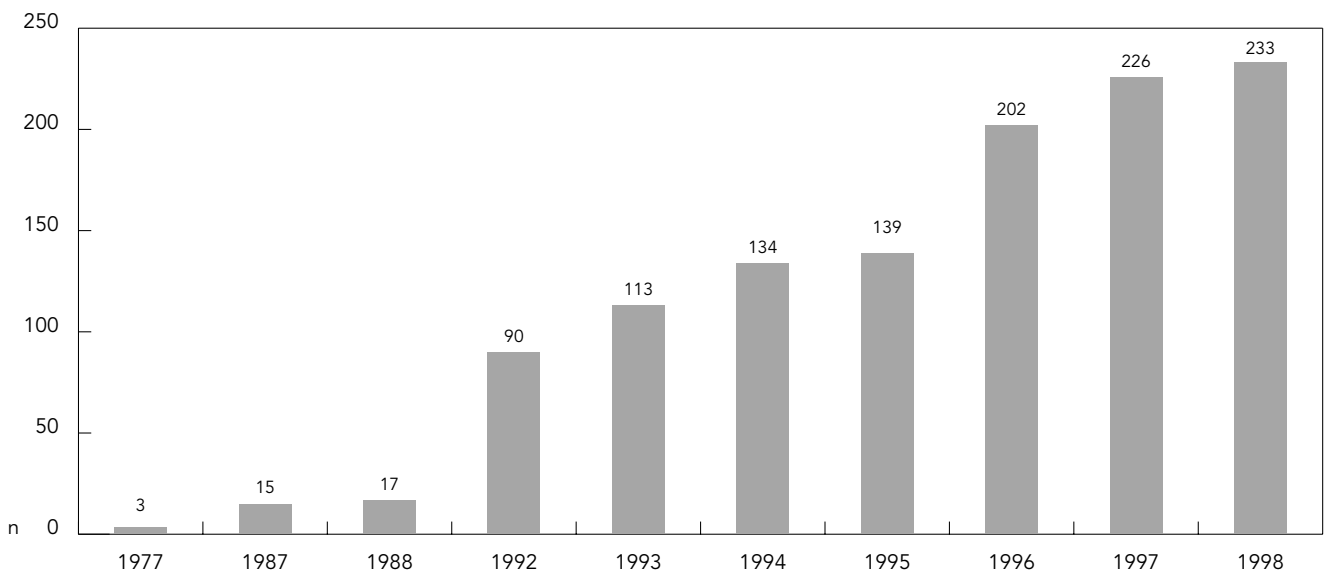

1992, quando passou a ser efetivamente desenvolvido o PLE, além da ampliação do volume de atendimentos programáticos realizados. Ressalta-se o incremento quantitativo predominante de atividades internas às unidades de saúde com concentração substancial naquelas de caráter curativo e individual.

Além dos encontros regionais de saúde, por categorias ou por áreas de atuação profissional (como exemplo, o Encontro de Odontologia Comunitária) que foram freqüentes nos anos 70 e 80 , passaram a ser muito relevantes na organização dos serviços, a partir da década de 90, as Conferências Municipais de Saúde (CMS), bem como as estaduais e as nacionais que ganharam destaque no que tange a participação democrática, desde a sua oitava edição em 1986. Tal processo culminou e orientou a política de saúde formalizada na Constituição de 1988 (Brasil, 1998), com o SUS.

Em Campinas foram realizadas cinco CMSs (agosto/1990, setembro/1991, novembro/1994, junho/1997 e fevereiro/2000). Nas quatro primeiras discutiram-se os modelos de atenção à saúde a serem geridos, os quais, na dependência da orientação política do governo e da SMS, eram mais ou menos amplamente discutidos no cotidiano das unidades sanitárias.

Destacamos as deliberações da $4 \underline{a}$ CMS, as quais abordaram o controle social, a organização da atenção e da assistência à saúde, a vigilância em saúde, a avaliação e controle, o financiamento e a questão dos recursos huma- nos. No bloco de deliberações relativas a recursos humanos, consideramos que o presente estudo é convergente com a necessidade assinalada de realizar trabalho conjunto com as universidades na preparação de pessoal e no desenvolvimento de estudos e pesquisas necessários à política municipal de saúde. Assim, passamos a enfocar na atualidade as práticas cotidianas das enfermeiras na rede básica de serviços de saúde no município de Campinas.

\section{As práticas das enfermeiras}

O uso da expressão práticas para designar as ações que compõem o trabalho das enfermeiras, justifica-se em função de vários processos que ocorrem na atualidade, dentre os quais destacamos o movimento internacional de classificação das práticas de enfermagem liderado pelo Conselho Internacional de Enfermagem (ICN). Uma análise preliminar dos sistemas de classificação de enfermagem existentes evidenciou um predomínio das classificações para assistência hospitalar. Diante dessa realidade, o ICN iniciou um projeto internacional para a saúde pública. No Brasil esse movimento tem sido conduzido pela Associação Brasileira de Enfermagem (ABEn, 1997) em parceria com o ICN, com apoio da Fundação Kellogg, e corresponde ao Projeto de Classificação Internacional das Práticas de Enfermagem em Saúde Coletiva. 
Dada a extensão do material disponível, ou seja, a descrição do cotidiano de trabalho de 162 enfermeiras que participaram nas oito oficinas de trabalho já antes mencionadas, procedeu-se, inicialmente, a consolidação de enunciados por meio de análise de conteúdo e composição de um mapa geral descritivo pelo método de saturação.

A construção desse mapa geral, possibilitou a configuração ampliada e representativa da percepção do conjunto de enfermeiras em relação ao seu próprio trabalho. A organização dos dados tomou por orientação certos eixos de ordenação, modo de olhar e apreender os dados, que resultaram da reflexão coletiva realizada pelo grupo coordenador do Projeto de Qualificação da SMS de Campinas apresentado anteriormente. A consolidação e organização dos mesmos, permitiu a construção de um quadro geral de todas as atividades que as enfermeiras indicaram realizar em seu cotidiano de trabalho. A quantificação dessas ações possibilitou visualizar que, do elenco geral de ações, $28 \%$ correspondem à atenção de caráter individual, 23,9\% à coletiva, 33\% referem-se a ações do campo gerencial na unidade de saúde e $13,8 \%$ são relativas à coordenação, organização, treinamento, controle e supervisão do trabalho de enfermagem.

Outra questão não menos relevante a considerar é aquela relativa à natureza própria dos dados trabalhados, ou seja, o discurso em uma dada instância material, a linguagem escrita. Seguindo a perspectiva teórica defendida por Orlandi (1996) a análise de discurso se ocupa do processo de constituição dos sentidos e não do conteúdo do discurso, apreender as palavras reconhecendo nelas um sentido próprio, um sentido já dado e evidente, é "dar" sentido, é interpretar. Entram em jogo no discurso, portanto, o movimento de "dar" sentido do sujeito que constrói o discurso e o "dar" sentido daquele que o lê. Nessa linha teórica, as palavras não são transparentes, podem sempre remeter a sentidos outros, diferente daquele que o leitor pensa ser.

Durante o movimento de análise, identificamos algumas marcas na construção do discurso que nos pareceram ser indicadores de um certo modo particular de dar significação ao trabalho de enfermagem. Destacamos, portanto, alguns aspectos mais reveladores da percepção que as enfermeiras apresentam em relação ao próprio trabalho e ao de enfermagem. De uma maneira geral, as ações desenvolvidas pela equipe de enfermagem estão contempladas entre aquelas realizadas pela enfermeira, no entanto, observamos alguns pontos que julgamos merecer destaque.
Às vezes, a expressão trabalho de enfermagem contempla as ações exclusivas da enfermeira (por exemplo consulta de enfermagem, curativos complexos), outras vezes o uso de certos termos ou enunciados, tais como: o auxiliar desenvolve atividades básicas, a auxiliar de enfermagem, pela própria formação, tem ação mais limitada na VISA (Vigilância à Saúde), indicam um distanciamento ou distinção, entre o trabalho da enfermeira e o da enfermagem.

No entanto, as marcas no tecido discursivo algumas vezes indicam um movimento oposto, ou seja, parece que as enfermeiras assumem parcelas restritas e específicas do trabalho de enfermagem e a enfermagem desenvolve o trabalho numa perspectiva mais integrada. Por exemplo: a enfermeira realiza exame de mamas e a enfermagem faz prevenção de câncer cérvico-uterino e mamário. Atividades e práticas relativas ao controle de qualidade de imunobiológicos administrados, ou seja, controle de temperatura na sala de vacina e a avaliação da situação epidemiológica aparecem somente entre as atividades desenvolvidas pela equipe de enfermagem, essa marca faz pensar que essas ações não figuram entre as prioritárias no trabalho das enfermeiras.

Entre o rol de atividades da enfermeira há, ainda, a descrição de tarefas, tais como: crônicos (transcrição de receitas) incluída no elenco de ações educativas; prognóstico, transcrição de anticoncepcionais e administração de vacinas entendidas como procedimentos; acidente de trabalho: verificação de papéis, confecção de impressos próprios para visita ao RN e adulto $\mathrm{e}$ levantamento de problemas e planejamento, consideradas como atividades burocráticas. Parece existir uma ênfase acentuada no momento particular da execução manual/técnica de certas tarefas que, em realidade fazem parte de uma ação ampla e planejada. Esse dado nos leva a supor a existência de uma visão deformada ou preconceituosa dessas profissionais em relação à prática que realizam.

Quando a ação da enfermeira ocorre junto ao usuário na recepção do serviço (incluindo triagem, encaminhamentos e orientações após a consulta médica) o indivíduo que recebe sua ação é nomeado de: paciente, pessoa, cliente, usuário. Quando se faz menção a ações relacionadas ao Conselho Local de Saúde, utilizase o termo população. Quando o usuário entra no fluxo interno do serviço ele é denominado como: mulher, adulto, idoso, criança, gestante, mãe de desnutrido, criança anêmica, crônico, hipertenso, diabético, faltoso, paciente de tisiologia, ou ainda, ele está substituído pelo uso de termos que reforçam, mais uma vez, a visão 
que decorre, predominantemente, do modelo clínico de atenção à saúde: pediatria, GO, puericultura, pré-natal, clínica, doenças crônicodegenerativas, urgência, emergência, politraumatizado, caso de dengue.

O emprego dos termos consulta de enfermagem, atendimento individual e atendimento de enfermagem, assistência direta às pessoas, atividades assistenciais, são referidos tanto nas atividades cotidianas da enfermeira quanto naquelas desenvolvidas pela equipe de enfermagem, sem distinção. De acordo com a Lei do Exercício Profissional de Enfermagem de 1986, a consulta de enfermagem é uma atividade exclusiva da enfermeira. De qualquer maneira, o modo de citação da mesma é pouco especifica$\mathrm{da}$, pouco precisa - consulta de enfermagem geral, consulta de enfermagem (no domicílio ou no $C S$ ) - ou decorre de demandas originadas das especialidades médicas instituídas - consulta de enfermagem (clínica e GO) e consulta de enfermagem (pediatria, GO, adultos, doenças crônico-degenerativas), esse dado é revelador do modo como as enfermeiras situam essa ação exclusiva no conjunto das ações de saúde.

Na mesma direção, descrições tais como, atendimento individual geral (queixas, transcrição de exames etc.), atendimento de mulheres, inclusive tratamento de leucorréias, atendimento de urgência (politraumatizados, gestante, imobilizações), atendimento individual de Programas (HA, DM, gestantes, GO), atendimento nos programas de saúde do município, Atendimento na Saúde da Mulher e Puericultu$r a$, podem estar indicando um entendimento de que essas ações não sejam próprias ou específicas da enfermagem. A "assistência de enfermagem" foi mencionada da seguinte forma: V.D./procedimentos/encaminhamentos/urgência. Também neste caso, o emprego de uma expressão distinta das outras não parece indicar um sentido diferente dos empregados nas denominações anteriormente citadas.

Houve também situações em que as enfermeiras registraram de modo explícito que entre as atividades que realizam, às vezes, ocupam o lugar de outro profissional, atender gestantes quando não tem vaga com GO, cobrir falta de auxiliar de enfermagem, fechar o CS quando o guarda está de folga, atender telefones e problemas, ou dar informações na ausência da coordenadora.

\section{Considerações finais}

A política de saúde constitui-se como resposta do Estado, em todos os seus níveis de governo, às necessidades da população em seu território específico. No caso das políticas públicas em geral e de saúde, em particular, estarão sempre em jogo interesses explícitos ou não, as ideologias, os poderes organizacionais, os interesses políticos e econômicos, projetos individuais, coletivos, partidários e a pressão dos grupos envolvidos ou atingidos, dentre outros (Carpintero, 1996).

A política de saúde efetivamente implementada em cada época, reflete o momento histórico em que foi formulada, as condições econômicas vigentes, os avanços do conhecimento científico, bem como a capacidade dos cidadãos, grupos e classes sociais se organizarem e influenciarem as definições políticas formais e informais.

Temos o SUS vigente em nosso país desde 1988. Contudo, a sua implantação e consolidação vem dependendo do cumprimento efetivo das leis e do interesse concreto dos seus guardiões em todos os níveis de governo e, especialmente, no nível local da atenção (e de governo) que se estrutura nos Centros de Saúde, com controles sociais ora mais, ora menos efetivos. Assim, no atual estágio da municipalização da saúde, o Município de Campinas conta com um quadro composto de 233 enfermeiras, $134(57,5 \%)$ delas atuando nos Centros de Saúde, 53 (22,7\%) nos Centros de Referência que oferecem atendimentos especializados, dez ocupando cargos na administração central, e $36(15,4 \%)$ nos níveis distritais, que respondem pela coordenação administrativa e técnica, especialmente na vigilância epidemiológica das atuais cinco regiões distritais de saúde.

As principais atividades desenvolvidas pelas enfermeiras na rede básica são o treinamento e supervisão do pessoal de enfermagem; a assistência e as ações educativas e preventivas nas áreas da criança e adolescente, mulher, adulto e idoso; bem como as ações de vigilância epidemiológica e sanitária. Esta última está passando por recente incorporação nos CSs. Destacam-se ainda, as atividades agrupadas na "co-gerência" junto ao coordenador da unidade local de saúde, que na maioria das vezes também é uma profissional enfermeira, tais como o planejamento das atividades do CS nas diferentes áreas de atenção; a organização de campanhas de vacinação e ações extra-muros e intersetoriais, junto às escolas, creches, indústrias, empresas e demais instituições de sua área de abrangência.

No atual planejamento da SMS para a qualificação das práticas de enfermagem estão previstas uma maior atuação da enfermeira na atenção direta à saúde dos usuários, incentivo 
ao registro efetivo e com qualidade da produção realizada, ampliação das ações extra-muros, das ações educativas e atividades grupais e coletivas. Fomentar tais práticas pode contribuir na efetiva consolidação do SUS em Campinas e no desenvolvimento de políticas públicas saudáveis no âmbito local, com inequívocas repercussões, ainda que restritas, no estado e no país como um todo.

\section{Referências}

ALMEIDA, M. C. P.; MISHIMA, S. M.; SILVA, E. M. \& MELLO, D. F., 1997. O trabalho de enfermagem e sua articulação com o processo de trabalho em saúde coletiva - Rede básica de saúde. In: $O$ Trabalho de Enfermagem (M. C. P. Almeida \& S. M. Rocha, org.), pp. 61-112, São Paulo: Cortez Editora.

ALMEIDA, M. C. P. \& ROCHA, J. S. Y., 1986. O Saber de Enfermagem e sua Dimensão Prática. São Paulo: Cortez Editora.

ABEN (Associação Brasileira de Enfermagem), 1997. Projeto de Classificação das Práticas de Enfermagem em Saúde Coletiva no Brasil. Manual do Pesquisador - Parte I: Orientação para o Trabalho de Campo. Brasília: ABEn.

BRASIL, 1975. Lei no 6.229 de 17 de Julho de 1975. Dispõe sobre a organização do Sistema Nacional de Saúde. Brasília: Diário Oficial da União, pp. 8921-8922, 18 jul. Seção I, pt. I.

BRASIL, 1986. Lei no 7.498 de 25 Junho de 1986. Dispõe sobre a regulamentação do exercício da enfermagem e dá outras providências. Brasília: Diário Oficial da União, pp. 9273-9275, 26 jun. Seção I.

BRASIL, 1996. NOB-SUS 01/96 - Norma Operacional Básica do Sistema Único de Saúde. Brasília: Ministério da Saúde.

CARPINTERO, M. C., 1996. Políticas de Saúde - Como e Porque se Constroem. Campinas: Centro de Educação dos Trabalhadores da Saúde, Secretaria Municipal da Saúde, Prefeitura Municipal. (mimeo.)

CARVALHO, G. C. M., 1993. O momento atual do SUS... A ousadia de cumprir e fazer cumprir a lei. Saúde e Sociedade, 2:9-24

MELO, C., 1986. Divisão Social do Trabalho e Enfermagem. São Paulo: Cortez Editora.
MENDES, E. V., 1994. Distrito Sanitário: O Processo Social de Mudança das Práticas Sanitárias do Sistema Único de Saúde. 2a Ed. São Paulo: Editora Hucitec/Rio de Janeiro: ABRASCO.

ORLANDI, E. L. P., 1996. Interpretação: Autoria, Leitura e Efeitos do Trabalho Simbólico. Petrópolis: Editora Vozes.

PEREIRA, M. J. B.; FORTUNA, C. M.; SILVA, E. M.; PINTO, I. C.; MISHIMA, S. M. \& ALMEIDA, M. C. P., 1997. Enfermeiros na rede básica de Ribeirão Preto e as políticas de saúde - Situação atual. In: Congresso Brasileiro de Saúde Coletiva, Resumos, p. 184. Águas de Lindóia: ABRASCO.

PIMENTA, A. L., 1993. O SUS e a municipalização à luz da experiência concreta. Saúde e Sociedade, 2:25-40.

REZENDE, A. L. M., 1986. Saúde-Dialética do Fazer e do Pensar. São Paulo: Cortez Editora.

SCHRAIBER, L. B., 1996. Ciência, trabalho e trabalhador em saúde: Contribuições de Ricardo Bruno Mendes Gonçalves para a compreensão da articulação entre saber, prática e recursos humanos. Divulgação em Saúde para Debate, 14:7-9.

SILVA, G. B., 1986. Enfermagem Profissional. São Paulo: Cortez Editora.

SMEK, E., 1986. Saúde e Democracia: Experiência de Gestão Popular. Um Estudo de Caso. Tese de Doutorado, Campinas: Faculdade de Ciências Médicas, Universidade Estadual de Campinas.

TANAKA, O. Y.; ESCOBAR, E. M. A.; GIMENEZ, A. S. M.; CAMARGO, K. S. \& LELLI, C. L. S., 1991. A municipalização dos serviços de saúde no Estado de São Paulo. Saúde em Debate, 33:73-79. 